\title{
How do supranational terms transfer into national legal systems?
}

\author{
A corpus-informed study of EU English \\ terminology in consumer protection directives \\ and UK, Irish and Maltese transposing acts
}

\author{
Łucja Biel \& Agnieszka Doczekalska \\ University of Warsaw $\mid$ Kozminski University
}

\begin{abstract}
The objective of this paper is to analyse how European Union (EU) supranational terms related to consumer protection transfer into domestic legal systems of three English-language jurisdictions (the UK, Ireland and Malta) during the transposition of EU directives. Transposition is a process of incorporating EU directives into national law and capturing supranational terms during their entry into national legal systems. We adopt a mixedmethod approach of corpus linguistics and legal analysis of terms, working with a corpus of five directives and their UK, Irish and Maltese transposing acts. Distinguishing between a term and a concept level, we propose a categorisation of transfer techniques arranged along a cline from foreignization to domestication. They involve imports, modifications (non-denominative and denominative variants), localisations and zero transfer both at the term level and the concept level.
\end{abstract}

Keywords: legal terms, supranational terms, autonomous legal concepts, EU terminology, transposition, directive

Transposition is a process through which national drafters incorporate European Union (EU) directives into their national law. This complex process is interesting from the terminological point of view, because it captures supranational terms, which designate autonomous concepts of EU law, during their transfer into national legal systems. That transfer poses numerous terminological and legal challenges. Despite the acknowledged importance of transposition for national legal terminology, this process remains curiously under-researched. The objective of 
this exploratory study is to analyse how EU supranational terms related to consumer protection are transferred into the domestic legal systems of three Englishlanguage jurisdictions, the UK, Ireland and Malta. With this objective in mind, we hope to gain a better understanding of the nature of EU supranational terms and their impact on national legal terminologies. We have adopted a novel mixedmethod approach that combines a quantitative approach of corpus linguistics with a qualitative legal analysis of the meaning of selected terms.

\section{EU supranational terms as a special category of legal terms}

As units of specialist knowledge (Sager 1998: 259), Language-for-Specific-Purposes (LSP) terms are typically associated with the relative universality of concepts across cultures (cf. Wilss 1994:38). In contrast, however, legal terminology, which is a product of national legal systems, stands out as strongly system-bound, largely incongruous between national legal systems and constrained within national borders (cf. Šarčević 1997: 232). Yet, supranational legal terms, which are terms used in legal frameworks of supranational and international organisations, such as the EU, have a much more complex profile, mainly due to the double legal environment they inhabit: the immediate supranational environment and more remote national environments (cf. Biel and Sosoni 2019:216). In these environments, they 'travel' through the compulsory implementation of EU law in the Member States' national law. We argue that, due to this 'travelling' requirement, supranational terms more easily transcend national borders and, hence, should be treated as a special category of legal terms. The further discussion will focus on the EU's supranational law.

The 'travelling' of supranational concepts between supranational and national environments is a staged process, which is comprised of drafting, authentication, entry into national systems, use and interpretation (see Chart 1). Roughly speaking, the first two stages take place at the supranational level, the next two take place in the national contexts of Member States, while the last one may take place both in the national and supranational environments. However, the division between supranational and national environments is not clear-cut as there are mutual influences and interdependencies at each stage.

The much-simplified life path of supranational concepts is visualised in Chart 1 and may be described as follows. At the drafting stage, a legislative proposal is prepared in most cases in the de facto drafting language, English, by the European Commission and translated into other official languages. The proposal moves through institutions and is consulted and negotiated in a multilingual manner with inter alia national governments and through the mediation of translators and interpreters (cf. Doczekalska 2018:169-170). After a political consensus is reached, 


\begin{tabular}{|c|c|c|c|c|}
\hline Drafting & Authentication & $\begin{array}{c}\text { Entry into } \\
\text { national legal } \\
\text { systems }\end{array}$ & Use & Interpretation \\
\hline $\begin{array}{l}\text { - Drafting a } \\
\text { proposal } \\
\text { - Translation } \\
\text { - Legal-linguistic } \\
\text { revision } \\
\text { - Consulting } \\
\text { and } \\
\text { negotiating a } \\
\text { proposal } \\
\text { - Final revision }\end{array}$ & $\begin{array}{l}\text { - Enactment by } \\
\text { EU } \\
\text { institutions } \\
\text { - Publication in } \\
\text { the Official } \\
\text { Journal } \\
\text { - All language } \\
\text { versions } \\
\text { become } \\
\text { authentic }\end{array}$ & $\begin{array}{l}\text { - Entry through } \\
\text { a direct } \\
\text { binding force } \\
\text { of EU } \\
\text { regulations } \\
\text { - Entry through } \\
\text { the } \\
\text { transposition } \\
\text { of EU } \\
\text { directives } \\
\text { after the } \\
\text { drafting of } \\
\text { national } \\
\text { transposing } \\
\text { law }\end{array}$ & $\begin{array}{l}\text { - Acquaintance } \\
\text { with legal acts } \\
\text { by their } \\
\text { addressees } \\
\text { - Potential } \\
\text { action (e.g. } \\
\text { entry into a } \\
\text { contract) } \\
\text { based on legal } \\
\text { acts } \\
\text { - Dissemination } \\
\text { of concepts } \\
\text { into other } \\
\text { genres and } \\
\text { contexts }\end{array}$ & $\begin{array}{l}\text { - Interpretation } \\
\text { of concepts by } \\
\text { national courts } \\
\text { - Interpretation } \\
\text { by the Court of } \\
\text { Justice of the } \\
\text { European } \\
\text { Union }\end{array}$ \\
\hline $\begin{array}{c}\text { Legislative } \\
\text { proposal }\end{array}$ & $\begin{array}{l}\text { EU legal acts } \\
\text { (regulation, } \\
\text { directive, etc.) }\end{array}$ & $\begin{array}{l}\text { - EU legal acts } \\
\text { - National } \\
\text { legislation in } \\
28 \text { Member } \\
\text { States }\end{array}$ & $\begin{array}{l}\text { - Various } \\
\text { practice-related } \\
\text { genres } \\
\text { (e.g. contracts) }\end{array}$ & - Judgments \\
\hline Supranational & Supranational & National & National & $\begin{array}{l}\text { National } \\
\text { Supranational }\end{array}$ \\
\hline
\end{tabular}

Chart 1. The life path of a supranational concept: Stages, processes, genres and contexts

a proposal is adopted by the European Parliament and the Council, published in the Official Journal (OJ) and becomes an EU legal act in 24 authentic, equally valid language versions (authentication), all of which contribute to its meaning (cf. Šarčević 2012: 86-87). Since the EU supranational legal system forms an inherent part of the Member States' legal systems, ${ }^{1}$ after the authentication, the EU legal act is introduced into 27 national legal systems (entry), where it becomes recontextualised in each national environment. Supranational terms enter the national scene in $27^{2}$ Member States. This occurs automatically if a legal act is directly applicable or through a transposition of directives into national legal systems. Next, supranational terms are used in practice in the Member States, when they are diffused into other contexts and genres and when EU citizens and other addressees base their behaviours on EU law (use). Finally, concepts are applied and interpreted by national courts. If doubts arise as to the interpretation of EU law, national courts

1. Case 6/64 Flaminio Costa v ENEL [1964] ECR 585, para 3.

2. 27 Member States from February 2020 due to Brexit. 
have a right, and in some cases a duty, to refer for a preliminary ruling to the Court of Justice of the European Union (CJEU), where cases are deliberated in French, the only working language of the Court. Thus, the final interpretation and fine-tuning of the meaning of supranational concepts is affected through case law (cf. Woods et al. 2017: 639), and the CJEU plays an active role in developing their autonomy through interpretation at the supranational level (Bajčić 2017: 80; 2018: 20). Of critical significance in the life path of supranational concepts is that, while they are created at the supranational level, they are applied in national legal systems (Kjær 2007: 79; Šarčević 2012: 89), and they are shaped through interpretation both at the national and supranational levels.

Arguing that supranational terms are a special category of legal terminology, we propose to describe them through three key properties: autonomy, multilingualism and continuity (in addition to the above-discussed travelling requirement).

The key distinctive feature of supranational concepts is their presumed autonomy. Thanks to the legal autonomy of the EU, its law has its own autonomous concepts which are peculiar to EU law and thus are system-bound, being independent of national legal systems (Doczekalska 2018: 174-175; see also EU case law). ${ }^{3}$ Furthermore, autonomy means that such concepts are expected to be uniformly understood by citizens and uniformly interpreted and applied by national courts in all of the Member States, ${ }^{4}$ be it France, Finland, Latvia, Bulgaria, Portugal, the UK, Ireland or Malta. This requires a 'common conceptualization' of EU concepts throughout the EU (Bajčić 2018:21). At the drafting stage, autonomy is linguistically achieved through institutionally controlled terminological choices, mainly through various forms of the cultural neutralisation of terms, which deterritorialises concepts to minimise terminological difficulties in translation and divergences between language versions. This includes the avoidance of terms of national law which are system-bound and do not have adequate equivalents in other EU languages or are too narrow/broad in meaning (as recommended in institutional guidelines; see General Secretariat 2002: 98; European Union 2015: 16). Instead, supranational terms are preferably formed through neutralisation techniques, such as the coinage of neologisms (Pozzo 2012:200), the use of generic terms in a specialised sense (Mattila 2013:157-158) and modifications of existing terms (Bajčić

3. e.g. Case 283/81 Srl CILFIT [1982] ECR 3415, ECLI:EU:C:1982:335.

4. The CJEU underlines in case-law the need for a uniform application of EU law. See, for instance, paragraph 32, Case C-467/o8 of 21 October 2010 Padawan SL v Sociedad General de Autores y Editores de España (SGAE), ECR 2010 I-10055, ECLI:EU:C:2010:620, stating that the "terms of a provision of European Union law [...] for the purpose of determining its meaning and scope must normally be given an independent and uniform interpretation throughout the European Union”. 
2017: 83). Ideally, thanks to these techniques, EU concepts should be denoted by semantically transparent and easy-to-translate terms, which explicitly signal to recipients that they deal with autonomous concepts of EU law (cf. Šarčević 2012: 105). Yet, although EU concepts are presumed to be autonomous, they are rarely completely new and original; they do not start 'from a tabula rasa' (cf. Prieto Ramos 2014:317). EU concepts tend to be inspired by, borrowed from and rooted in concepts of national legal systems (Doczekalska 2018:175; Kjær 2007: 79; Bajčić 2017:83), and adjusted by a new layer of meaning through 'legal engineering' (Prieto Ramos 2014:318). As a result, it may sometimes be difficult to establish whether a given concept is autonomous and has an EU meaning or belongs instead to national law, and its meaning should be established through national legal scholarship and case law (Doczekalska 2018:175).

Multilingualism is related to the fact that EU law is simultaneously enacted in 24 authentic language versions of an equal basis. Thus, as shown in Chart 2 below, EU legal concepts are designated linguistically in 24 equivalent terms in 24 official languages (referred to by EU institutions as 'multilingual concordance', DGT 2016: 4) and interact with 27 national legal systems, legal languages and concept systems.

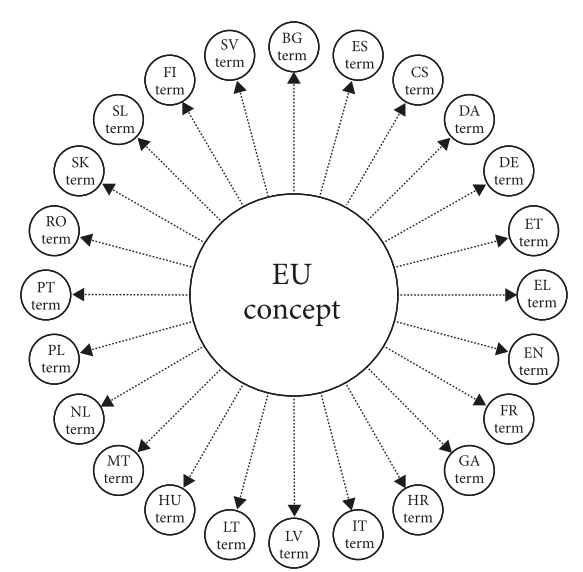

Chart 2. Denominations of an EU concept in 24 official languages at the supranational level

Drawing on Sager's distinction between primary and secondary term-creation (1990) and based on the institutions' actual practice, Fischer (2010) distinguishes between the 'multilingual primary term-creation' in the case of the drafting languages (English, French, German), the process which is authored by EU civil servants, experts and politicians, and between the 'intra-conceptual term-transfer', a secondary process effected through translation into the other official languages 
within the EU conceptual systems (2010: 29). ${ }^{5}$ Considering the dominant role of English as a drafting language, the first process may currently be more accurately described as a 'primary term-creation. From the terminological point of view, the primary-term creation in English at the drafting stage differs from the intraconceptual term-transfer at the translation stage for the other languages, even though, from the legal point of view, all language versions become equally authentic after authentication and secondary terms become primary terms regardless of the fact that they were formed through translation. Fischer calls the process through which the EU terms are transferred into national legal systems 'interconceptual term-transfer' due to an involvement of more than one conceptual system (2010:32). As a result, supranational terms are associated with the inherent involvement of translation, extreme filtering of content through other languages and cross-linguistic mediation behind multilingualism.

Finally, another important feature of supranational terminology is the continuity, also known as consistency, of terminology internally and with the terminology used in the higher-ranking legal acts (in particular the primary legislation) and in the existing body of EU legal acts (Robertson 2015:42). This is also an institutional guideline for drafters and translators (European Union 2015: 20). The continuity requirement is connected with the systemic nature of law, which in the EU context is placed in both vertical dimension of the existing and future texts in a given language as opposed to the horizontal dimension of multilingual versions of a legal act (Robertson 2015: 41, cf. Biel 2019 for further discussion).

This section has characterised supranational legal terms, pinpointing their distinctive features: autonomy, multilingualism, continuity, and complex staged travelling through supranational and national contexts. The further discussion will focus on a specific stage in the life of EU supranational terms - their entry into the Member States' national legal systems through transposition.

\section{Transposition of directives into the Member States' national legal systems and its impact on national terminology}

The EU applies two main forms of legal acts, regulations and directives, to harmonise the Member States' laws. Regulations are binding in their entirety and are directly applicable in all Member States. They become an integral component of national legal systems, and their key role is to unify national legal systems across the EU. Directives bind the Member States to the objective which is to

5. Drawing on Fischer, Temmerman refers to 'multilingual neology creation', that is the formation of 24 Euro-neologisms - European primary neologisms and secondary terms (2018:11-12). 
be achieved, leaving them the choices of form and methods (Article 288 of the Treaty on the Functioning of the European Union, TFEU). Thus, directives are a 'framework law' (Bradley 2017: 100) and a tool to harmonise the laws of Member States, respecting their distinct legal traditions and the specificity of legal systems 'with as little interference as possible in their own laws, national terminology and conceptual system as a whole' (Šarčević 2012: 90). Transposition is an instance of Jakobsen's intralingual translation or rewording (cf. Jakobsen 1959:233; Kjær 2007:77), whereby directives are 'translated' from a supranational EU language to national legal languages and localised into national legal environments (Biel 2014:59). A linguistic consequence is that, compared to regulations, directives tend to be formulated in a more flexible (Fairhurst 2007:62), general and vague language (Šarčević 2012: 91).

Since directives are not directly binding on the Member States; they have to be implemented into the States' national legal systems. The implementation has two phases: a transposition and an application. Transposition consists of the drafting of a new national legal act or amending the existing legislation to achieve an objective set out in the directive. The second phase of implementation is an application of national legislation, which transposes the directive, including its interpretation by courts. This paper covers only the transposition phase of the implementation.

A fundamental choice to be made by national drafters during the transposition is the extent to which national transposing provisions will depart from the wording of a directive, which may range along a cline from the copy-out technique to the elaboration technique at the other extreme. The copy-out technique copies the provisions of the directive nearly verbatim. It has gained in popularity as a safeguard against the under-implementation or over-implementation of a directive (cf. Robinson 2017:234). For example, this technique has been recommended by the UK government in its transposition guidelines ${ }^{6}$ since 2013 precisely to avoid 'gold-plating', which is over-implementation that goes beyond the necessary minimum requirement of the directive and creates unintended consequences or additional obligations in a transposing act (HM Government 2018:8). As Robinson observed, the main issue with the copy-out technique is that, since directives tend to be written in a less precise manner, copied-out national provisions will lack 'the requisite precision' (2017: 235). The other technique - elaboration - departs from the exact wording of the directive 'to clarify its meaning for

6. Rule $5 \mathrm{~d}$ of the Guiding principles for EU legislation (BIS, 2013) requires that departments 'always use copy out for transposition where it is available (...). If departments do not use copy out, they will need to explain to the RRC the reasons for their choice.' (https://www.gov.uk /government/publications/guiding-principles-for-eu-legislation, accessed 6.1.2019). 
legal or domestic policy reasons' (HM Government 2018:8). The CJEU has confirmed that the obligation to transpose a directive does not automatically mean that its provisions have to be 'formally incorporated verbatim' 'in precisely the same words' in national law if the general legal context ensures its full application 'in a sufficiently clear and precise manner', and in some cases Member States may not need to take any legislative action at all.

The choice of transposition technique may be limited by a type of harmonisation method adopted in a directive. In particular, the copy-out technique may be triggered by the maximum harmonisation method required in a directive (as opposed to the minimum harmonisation method). With full (or maximum) harmonisation, a policy area is fully and exhaustively regulated at the EU level. The Member States must ensure full compliance and have very limited transposition leeway (sometimes none) to adjust it to a State's national tradition and legal language, having no further competence in that area (Woods et al. 2017:338, 340). In this case, a directive resembles a regulation and tends to regulate a policy area in considerable detail. A Member State may not introduce or retain national provisions that are inconsistent with the directive. For example, in the case of consumer protection, national provisions may not provide a higher level of protection, which would be possible in the case of directives with minimum harmonisation. Until 2005, consumer protection directives were based on the minimum harmonisation method due to significant differences between the Member States and the lack of political consensus. This adversely affected consumer protection in the EU. The first consumer protection directive based on full harmonisation was the Unfair Commercial Practices Directive (2005/29/EC), which is one of the directives covered by this analysis. Although it contains some provisions which give leeway to the choice of implementation method, it resembles a regulation to a large extent (Reilly 2009: 112).

It may be expected that full harmonisation will increase the impact of EU terminology on national languages, especially when directives create new legal concepts. This was the case with the Unfair Commercial Practices Directive, which introduced a new model of consumer protection that was not derived from existing solutions in the Member States (Abbamonte 2007:31). To achieve full harmonisation, it is important not to depart excessively from the terminology used in directives during the transposition, because EU concepts are required to be understood and applied in the same way throughout the EU (Eriksson and Öberg 2007:93). Reilly argues that it is theoretically possible to transpose a directive based on full

7. Judgments of the Court, Case C-217/97 Commission v Germany [1999] I-5087 ECLI: EU:C:1999:395, paras 31 and 32; and C-131/88 Commission v Germany, [1991] I-825 ECLI: EU:C:1991:87, para. 6. 
transposition by translating its provisions into a more familiar national language provided that it does not significantly depart from the directive. However, such departures increase the risk of inadequate transposition (Reilly 2009:112). A similar risk appears when drafters explain vague and ambiguous concepts of a directive (Reilly 2009: 112). Thus, the copy-out technique seems to be the 'safest' method to transpose a directive which requires full harmonisation.

It is important from the terminological point of view that transposition requires a transfer of supranational legal concepts into national legal systems (i.e. inter-conceptual term-transfer, Fischer 2010:32). At this phase, national drafters face challenges connected with a choice of adequate terms to denote supranational concepts. Transfer techniques will be examined in Section 6.

\section{EU law: Consumer protection law as a case in point}

From among a wide range of fields regulated by EU law, we have selected consumer protection law, which is an essential element of the Internal Market. Its main objective is to harmonise consumer protection throughout the EU by protecting consumers' 'health, safety and economic interests' and 'promoting their right to information, education and to organise themselves in order to safeguard their interests' (Article 169 TFEU). EU consumer law protects consumers as a weaker party in contractual and non-contractual dealings with traders (Šarčević 2012: 98), giving the EU 'a social face' and at the same time removing excessive barriers to trade (Howells 2017:687). The key instruments of EU consumer law include information obligations to enable consumers to make informed decisions and consumers' right to withdraw from certain types of contracts (Howells 2017: 687-695).

One of the reasons for our choice of consumer protection law was the fact that consumer protection at the national level is strongly affected by the EU level: 'Few areas of national law have been influenced as heavily by EU law as consumer protection' (Howells 2017:686). Secondly, this area has been traditionally regulated by directives rather than regulations (Howells 2017: 691). The third reason is the predominantly private-law nature of consumer protection law and hypothesised terminological challenges. Although there is no consensus as to how this area of law should be classified (Kunkiel-Kryńska 2013), whether as a separate and coherent branch of EU law or as part of civil law, the majority of consumer law provisions are of a private-law nature. ${ }^{8}$ Private law is strongly rooted in Member

8. Consumer protection was included in the scope of work on common frames of reference in the areas of European private law (DCFR) and European contract law (cf. Schulte-Nölke 2008: 29 and Commission Decision 2010/233/EU). 
States' legal traditions, and EU consumer protection law unavoidably uses common core concepts from contract law and tort law, e.g. consumer, contract, goods, damage with conceptual divergences in national legal systems (Šarčević 2012: 98). This triggers difficulties with effective harmonisation and the integration of new solutions in national legal systems, which makes EU consumer law a challenging area to transpose.

\section{EU English and national legal Englishes}

The study analyses the transposition of EU consumer law directives into the national legal systems of the UK, Ireland and Malta, and our focus is on English versions of legal acts. All three countries use English as an official language in which they draft their national legislation. The choice of English is motivated by a few factors. First, despite the declared equality of all $24 \mathrm{EU}$ official languages, English is a de facto working language of the EU institutions involved in the drafting process. For practical reasons, first versions of legislative acts are drafted, consulted and negotiated mainly in English (Doczekalska 2018: 169-170), or rather in its deculturalised neutral variety, EU English, predominantly by non-native speakers of English (cf. Pozzo 2012; Biel et al. 2018:250-254 for further discussion). Furthermore, as a legal language, English is associated with the language of common law. Even though it should have caused substantial difficulties since the majority of Member States have civil law systems, English turned out to be a good source of neutral terminology, which avoids system-bound terms of English law. Thus, it will be interesting to explore what happens to neutralised EU terms when they are transposed into other English-language jurisdictions. Overall, this research setup allows us to control the variable of interlingual translation to some extent.

The UK, Malta and Ireland have distinct legal systems and, hence, distinct legal languages and concept systems. In respect of the UK, our analysis is limited to English law, that is the common law system of England and Wales, excluding the laws of Scotland and Northern Ireland, which have a mixed legal system with common law and civil law elements (Gillespie and Weare 2017: 12). Malta also has a mixed legal system influenced both by English law (a UK colony until 1964), especially in the area of procedural and administrative law, and continental law, in particular Italian law (Micallef 2013:237). Ireland has a common law system which, to a large extent, resembles English law, since, after it regained independence in 1921, Ireland modelled its legal system on the English one. The main difference between the English and Irish legal systems lies in the written constitution adopted by the latter (Binchy 2011: 153). In respect of common law countries, such as the UK and Ireland, what may be challenging during transposition is limited 
statutory regulations and, hence, the lack of established consumer protection terminology, because such protection is developed mainly in case law (Donnelly and White 2014:7-8). Finally, there are some differences in the implementation of EU law. The UK and Ireland joined the EU in $1973^{9}$ and were transposing directives into their law on an ongoing basis, while Malta acceded in 2004 and was required to harmonise its law before the accession. Consumer law is a new area of regulation, and initially neither of these countries had a complete system of consumer protection, with national provisions scattered across a range of legislative acts.

Ireland and Malta have bilingual legislation: Ireland in English and Irish while Malta in English and Maltese. Both Irish and Maltese are also EU official languages. However, our study is limited to the English-language versions of transposing acts.

\section{Material and method}

The study is based on five influential horizontal consumer protection directives ${ }^{10}$ listed below and their UK, Irish and Maltese transposing acts (documented in the Appendix).

1. Unfair Contract Terms Directive (UCT) (93/13/EEC)

2. Consumer Sales and Guarantees Directive (1999/44/EC)

3. Unfair Commercial Practices Directive (UCP) (2005/29/EC)

4. Misleading and Comparative Advertising Directive (2006/114/EC)

5. Consumer Rights Directive (CRD) (2011/83/EU)

These are fundamental directives of EU consumer protection law. Two of the directives are from the 1990 s and were subject to minimum harmonisation, while three directives were enacted from 2005 on and were subject to full (or mixed) ${ }^{11}$ harmonisation. They cover a span of nearly 20 years.

The study adopts a mixed-method approach, combining a quantitative approach of corpus linguistics with a qualitative legal analysis of selected terms. A range of corpus methods (cf. McEnery and Hardie 2012), in particular wordlists,

9. The UK left the EU on 31 January 2020.

10. These directives provided substantive consumer protection rules and were chosen for general evaluation at the EU level (Fitness Check of 4 directives from the corpus and parallel evaluation of Directive 2011/83/EU); for further information consult https://ec.europa.eu/newsroom /just/item-detail.cfm?item_id=59332.

11. E.g. Directive 2006/114/EC stipulates minimum harmonisation in respect of misleading advertising and full harmonisation in respect of comparative advertising (Article 8). 
keyword lists, n-grams, term extraction and concordances, was used to identify terms systematically and to study their behaviour from a macro-perspective. Because of an exploratory nature of the study, we opted for a relatively small but thematically-controlled corpus (total corpus size: EU directives - 34,125; UK 123,403; Maltese - 78,511 and Irish transposing acts - 50,855 words), further split into five sections for each directive and its transposing acts, to which we will refer as 'sets' Two concordancers were used: Wordsmith Tools 7.0 (Scott 2016) and Sketch Engine (Kilgarriff et al. 2014), where files were automatically tagged in the latter.

\section{Analysis of EU terms in transposition into national legal systems}

\subsection{Terms which resist travelling: Absences in transposing acts}

The first stage of the analysis was to identify terms which strongly resist travelling to national contexts, that is EU terms which were not transferred from the directives to all of the national transposing acts. For this purpose, working with Sketch Engine's term extraction function, ${ }^{12}$ we extracted multi-word terms for each directive, setting its national transposing acts as a reference corpus. We next selected terms which had a zero frequency in the reference corpus of the UK, Maltese and Irish transposing acts. They were manually cleaned of non-terms and overlaps, analysed through concordances and categorised in Excel.

As a result, we identified 21 multi-word terminological units in Directive 93/ 13/EEC, 24 in Directive 1999/44/EC, 52 in Directive 2005/29/EC, 28 in Directive $2006 / 114 / \mathrm{EC}$ and $88^{13} \mathrm{in} 2011 / 83 / \mathrm{EU}$, which were absent in all corresponding transposing acts. These terms can be categorised as follows. A sizeable group includes terminology related to a legislative process, e.g. legislative proposal, ordinary legislative procedure, official publication, correlation table, full/minimum/partial harmonisation, transposition measures, existing acquis, including terms related to the structure of legislative acts, e.g. paragraph, subparagraph, annex. The legislative procedure terminology is not transferred, since it forms part of the instructions for national drafters. Terms connected with the legislative style are usually domesticated in line with national drafting traditions, for example an annex becomes a schedule in all national jurisdictions (UK, IR - Ireland, MT - Malta). Another category of absent terms are generic terms, which are sufficiently broad to cover var-

12. Sketch Engine identifies terms as multiword noun phrases, which meet term definition rules and are typical in a study corpus against a reference corpus (cf. https://www.sketchengine .eu/wp-content/uploads/ske-statistics.pdf).

13. A higher number due to a significantly larger size of this directive. 
ious local solutions, and which are replaced by more specific national terms at the drafting stage. A good example is a frequent term administrative authority (and related administrative body, national authorities), which is replaced by more familiar terms of national law, e.g. enforcement authority, enforcer (UK), local authority (Ireland) or specific national institutions, e.g. the Consumer Claims Tribunal (MT), Financial Services Authority (IR), OFT (UK). The next category of terms which resist transfer covers the general terminology of EU law, e.g. internal market, free movement, non-member country, cross-border (healthcare, sale), and union-wide model. They are connected with the EU perspective of directives, which is replaced by national perspectives in transposing acts. This category of absences, but not only, may also be attributed to an interdiscursive structure of directives which contain preambles explaining the rationale, describing the political, legal and social context, and illustrating the meaning of new concepts with examples or exclusions, e.g. beach resort, dental practitioner, natural gas, corporate promotional literature. In fact, the majority of absences come from preambles; some of them are used in a less rigid manner as variants of legal terms, e.g. typical consumer instead of average consumer, out-of-court settlement alongside amicable settlement and registered trade mark alongside trade mark and protected trade mark. A relatively small number of absences in all transposing acts concerns consumer protection and related terminology, e.g. non-contractual liability, contractual remedy, average consumer test, fair competition, and economic sector. Some terms are subject to modifications in national legislation, e.g. an economic sector becomes a business sector while unlawful comparative advertising becomes prohibited comparative marketing communication (IR) or comparative advertising which is not permitted (UK). Thus, concepts are transferred but under a different linguistic expression. Absences of consumer protection terms in national jurisdictions may also mean that (1) a concept was imported without a term, or (2) a legal provision containing a term was not transposed (zero transfer), either because of an inadequate implementation of a directive or because an objective of a directive is achieved through a different legal solution. For example, Malta did not transpose an exclusion of individually negotiated terms from unfair terms, and hence this term and this concept are absent in its transposition of Directive 93/13/EEC. Modifications will be discussed in Section 6.3.

\subsection{Terms which travel easily: A degree of overlap and imports}

Although corpus methods are generally regarded as biased against similarities and oriented at differences, it is possible to measure a degree of overlap, and hence similarity, between files and identify shared multi-word sequences with the $n$ - 
gram method. For this purpose, we generated lists of $2-6$ grams $^{14}$ in Wordsmith for each set of texts. We extracted n-grams that appear in all four texts in each set using Wordsmith's text dispersion information. The number of n-grams shared in each EU directive and its transposing acts is shown in Column 1 in Table 1. To gain insight into the degrees of EU n-gram overlaps with the UK, Malta and Ireland separately, we generated similar lists of shared n-grams for each country (Columns 2-4). ${ }^{15}$

Table 1. N-grams shared in EU directives and their transposing acts

\begin{tabular}{|c|c|c|c|c|}
\hline & Column 1 & Column 2 & Column 3 & Column 4 \\
\hline Shared n-grams & EU, UK, MT, IR & $\mathrm{EU} \& \mathrm{UK}$ & EU \& MT & EU \& IR \\
\hline \multicolumn{5}{|c|}{ Directive 93/13/EEC, size: 3,389 words, \# of 2-6 grams: 13,292} \\
\hline $2-6$ grams & 2265 & 5415 & 2901 & 5323 \\
\hline \% EU 2-6 grams & $17 \%$ & $41 \%$ & $22 \%$ & $40 \%$ \\
\hline \multicolumn{5}{|c|}{ Directive 1999/44/EC, size: 4,114 words, \# of 2-6 grams: 14,656} \\
\hline $2-6$ grams & 830 & 1467 & 3617 & 3477 \\
\hline \% EU 2-6 grams & $6 \%$ & $10 \%$ & $25 \%$ & $24 \%$ \\
\hline \multicolumn{5}{|c|}{ Directive 2005/29/EC, size: 8,843 words, \# of $2-6$ grams: 28,892} \\
\hline $2-6$ grams & 2648 & 7541 & 10793 & 3703 \\
\hline$\%$ EU 2-6 grams & $9 \%$ & $26 \%$ & $37 \%$ & $13 \%$ \\
\hline \multicolumn{5}{|c|}{ Directive 2006/114/EC, size: 2,907 words, \# of 2-6 grams: 10,349} \\
\hline $2-6$ grams & 716 & 1714 & 2327 & 995 \\
\hline$\%$ EU 2-6 grams & $7 \%$ & $17 \%$ & $22 \%$ & $10 \%$ \\
\hline \multicolumn{5}{|c|}{ Directive $2011 / 83 / E U$, size: 16,310 words, \# of 2-6 grams: 48,062} \\
\hline $2-6$ grams & 8268 & 11333 & 20381 & 11501 \\
\hline$\%$ EU 2-6 grams & $17 \%$ & $24 \%$ & $42 \%$ & $24 \%$ \\
\hline
\end{tabular}

The n-gram approach can measure the degree to which national drafters rely on the wording of EU directives, which is expressed both as a number of shared bundles and their percentage. Table 1 demonstrates that such reliance differs across

14. Frequency thresholds were set at the minimum level, e.g. a bundle shared in 4 files at 4 occurrences, i.e. at least 1 occurrence in each file.

15. To identify overlaps and absences, all versions of a transposing act (repealed and amending, if applicable) were merged into one file. 
directives, countries and time periods. The first $(93 / 13 / \mathrm{EEC})^{16}$ and the last directives $(2011 / 83 / \mathrm{EU})$ clearly affected national languages to the greatest extent, with a more than $40 \%$ overlap of $n$-grams in the UK and Ireland for the former and Malta for the latter. The n-grams jointly shared in all transposing acts amount to $17 \%$, while this percentage is much lower for the remaining directives, ranging from $6 \%$ to $9 \%$. Different percentages of overlaps also attest to shifts in harmonisation techniques. Except for the first directive, Malta shows the highest reliance on the wording of EU directives with overlaps from $22 \%$ to $42 \%$, which suggests a strong preference for the copy-out technique. Ireland and the UK do not seem to have had a consistent approach to harmonisation over this period, yet Ireland has steered towards elaboration since the 200os, to a greater extent than the UK.

Although n-grams obviously cannot be equated with terms, a substantial majority of them contain terms and their collocations. Owing to differences in legislative styles and a high lexical density of legislation, shared n-grams are rarely purely grammatical patterns. We can confirm that the directives and transposing acts share a broad range of single-word fundamental terms, e.g. consumer, producer, trader, manufacturer, representative, competitor, carrier, contract, guarantee, guarantor, goods, products, purchase, sale, payment, cost, delivery, supply, loss, damage, compensation, remedy, repair, injury, dispute, arbitration, evidence, and harassment. These terms often form larger terminological units (multi-word terms), which is where differences start to show among transpositions; hence, our focus on multiword terms. The next step was to isolate multiword consumer protection terms shared by the directives and their transposing acts by time-consuming manual cleaning, coding and sorting of n-gram lists. This method allowed us to identify terminological units that were imported ${ }^{17}$ (cf. Whittaker 2014:6) - copied out verbatim - from the directives into all national transposing acts of a set (Table 2).

Table 2. Imported multiword terms and collocations isolated from shared n-grams

\begin{tabular}{lcc}
\hline Directive & Terms & Verb + noun collocations \\
\hline $93 / 13 /$ EEC & 40 & 29 \\
$1999 / 44 / \mathrm{EC}$ & 24 & 6 \\
$2005 / 29 / \mathrm{EC}$ & 71 & 25 \\
$2006 / 114 / \mathrm{EC}$ & 22 & 6 \\
$2011 / 83 / \mathrm{EU}$ & 128 & 49 \\
\hline
\end{tabular}

16. The high reliance on the wording of the directive despite it being subject to minimum harmonisation.

17. We prefer to use the term import rather than transplant, which has a specialised meaning in comparative law. 
Given the number of $\mathrm{n}$-grams for each directive, the relatively largest number of imported terms and collocations was noted for 93/13/EEC, while the lowest was for 1999/44/EC. Imports include not only multiword terms but also their collocations and even much longer phrases in which such terms are embedded (e.g. excluding or hindering the consumer's right to take legal action or exercise any other legal remedy, 93/13/EEC).

Among n-grams, we separated collocations of terms with verbs, e.g. to purchase a product, supply goods or services, enforce a contractual obligation, cease trading, reimburse the price paid, withhold reimbursement, and discredit or denigrate trademarks. A substantial number of such collocations is consistent with national usage and hence, in most cases, copied back. Some neutralised, system-bound and semi-legal collocational variants can be found across the directives. This is well visible in a broad range of collocates of the key term contract, some of them synonymous, which are copied out in transpositions, e.g. to form, conclude, sign, perform, alter, extend, rescind, cancel, withdraw from, dissolve, and terminate a contract. Directives may occasionally introduce a new verbal collocation to denote a supranational concept, which may be illustrated with one notable collocation to materially distort the economic behaviour of consumers, elevated to the status of a defined term and imported in transpositions.

Terms that are imported in all jurisdictions can be grouped around the frame ${ }^{18}$ of commercial transactions (sales and service provision) with consumers. The components of the frame are as follows:

- $\quad$ trader (seller of goods; trader; trade, business, (craft) or profession; the producer or his representative; natural person; business premises; place of business; trading name; identity of the trader; professional diligence), consumer (average consumer, natural person, death of a consumer);

- pre-sale activities: invitation to purchase; initial transaction; ordering process, information and advertising addressed to consumers: informed choice; informed transactional decision; material information; marketing material; commercial communication; misleading advertising; bait advertising; pyramid promotional scheme; false information; in plain intelligible language; durable medium; direct exhortation to children;

- products and services offered: product or service; goods and services; consumer goods; provision of services; fitness for purpose; trade mark; distinctive sign; distinguishing marks; designation of origin; commercial origin; immovable property; industrial, commercial or intellectual property rights; digital

18. Our understanding of a frame derives from Frame-Based Terminology (cf. Faber Benítez et al. 2005). 
content; financial services; timeshare long-term holiday product; passenger transport services; service-provision scheme;

- sales: transactional decision; sale of goods; distance sales; simultaneous physical presence of the trader; public auction; bidding procedure; automatic vending machines; automated commercial premises; excursion organised by the trader; immovable retail premises;

- contract: terms, subject matter, duration, conclusion of the contract; contractual obligation; contractual right; party to the contract; conformity with the contract; copy of the signed contract, types of contracts - consumer contracts; contract of sale; sales contract; distance contract; off-premises contract; service contract; contract of fixed duration; contract of indeterminate duration; ancillary contract; holiday product resale and exchange contract;

- guarantee: commercial guarantee; guarantee statement; name and address of the guarantor; territorial scope;

- price and payment: charges or costs; price of goods; final price; total price; adequacy of the price; price advantage; extra charge; gratis, free, without charge; billing period; immediate or deferred payment;

- delivery: delivery of goods; standard delivery; supply of sealed goods; unsolicited supply of goods; supplied on a tangible medium; time of delivery; costs of delivery; supplementary costs; freight, delivery or postal charges; acknowledgement of receipt; (acquire) a physical possession of the goods;

- after-sale services: complaint handling policy; return; repair; repair and replacement; after-sale customer assistance; after-sales services;

- disputes: legal remedy; to take disputes (exclusively) to arbitration; out-ofcourt complaint and redress mechanism; legal proceedings; legal action; court complaint; burden of proof; factual context.

A substantial group of shared terms shows a negative prosody whereby they denote circumstances that disadvantage consumers during commercial transactions, e.g. unfair terms; total or partial non-performance or inadequate performance (of a contract); lack of conformity of the goods with the contract; significant imbalance in the parties' rights and obligations under the contract; significant inconvenience to the consumer; aggressive commercial practices; bait and switch; harassment, coercion or undue influence; use of threatening or abusive language; defective sample; loss or damage; mental or physical infirmity, age or credulity; exploitation of misfortune or circumstance; personal injury. These negative circumstances are identified in the directives to ensure that consumer protection is more likely to be imported than modified. Our tentative explanation can be that these terms tend to appear in provisions the violation of which entails some liability (sanctions), and hence national 
drafters may be reluctant to substitute or modify such terms not to affect the scope of liability. ${ }^{19}$

A special category of terms that travel easily into national environments are terms which are defined in the definitions section of directives. Definitions standardise the meaning of a legal concept and indicate how it should be interpreted throughout the EU. By virtue of definitions, such terms become salient. The directives covered by the analysis define 41 terms in the definitions section, the majority of which were imported into all national transposing acts $(\mathrm{UK}-37, \mathrm{MT}-35$, IR - 34) (Table 3).

Table 3. Terms defined in the EU directives and imported in transposition

\begin{tabular}{|c|c|c|}
\hline Directive & \# of imports/ defined terms & Imported terms \\
\hline $\begin{array}{l}93 / 13 / \\
\text { EEC }\end{array}$ & $2 / 3$ & unfair terms; consumer \\
\hline $\begin{array}{l}1999 / 44 / \\
\text { EC }\end{array}$ & $4 / 6$ & consumer; consumer goods; producer; repair \\
\hline $\begin{array}{l}2005 / 29 / \\
\mathrm{EC}\end{array}$ & $9 / 12$ & $\begin{array}{l}\text { consumer; trader; product; to materially distort the } \\
\text { economic behaviour of consumers; code owner; } \\
\text { professional diligence; invitation to purchase; undue } \\
\text { influence; transactional decision; }\end{array}$ \\
\hline $\begin{array}{l}2006 / \\
114 / \mathrm{EC}\end{array}$ & $1 / 5$ & trader \\
\hline $\begin{array}{l}2011 / 83 / \\
\mathrm{EU}\end{array}$ & $14 / 15$ & $\begin{array}{l}\text { consumer; trader; goods; sales contract; service } \\
\text { contract; distance contract; off-premises contract; } \\
\text { business premises; durable medium; digital content; } \\
\text { financial service; public auction; commercial } \\
\text { guarantee; ancillary contract }\end{array}$ \\
\hline
\end{tabular}

Finally, the question arises whether EU terms are imported together with their concepts. This question will be addressed in Section 6.4.

\subsection{Modifications and localisations of terms during transposition}

While a substantial number of EU consumer protection terms are imported into transposing acts, some modifications can also be observed. Terminological mod-

19. A similar rationale for the copy-out transposition of provisions that are connected with sanctions may be found in the explanatory note to the Polish transposition of Directive 2005/ 29/EC (https://bip.kprm.gov.pl/ftp/kprm/dokumenty/o70502u5uz.pdf). 
ifications were identified through Sketch Engine's term extraction function and Excel formulas. They can be classified as follows:

- Non-denominative variants: morphological variants - contractual term(EU), contract term (UK); communication medium (EU, MT), communications medium (IR); permutation - complaint handling (EU, MT), handling of complaints (UK); recategorisation - proof of actual loss (EU), to prove actual loss (MT), by repair or replacement (EU, MT, IR), to repair the goods or to replace the goods (UK); grammatical explicitation, which reduces a 'termness' of the term (cf. Shelov 1982, qtd. in Picht and Draskau 1985) - goods made to the consumer's specifications (EU, a defined term), goods that are made to the consumer's specifications (UK); communication medium (EU, MT), medium used to communicate the commercial practice (UK). Since denominations are retained, this seems to be a relatively safe technique.

- Addition of a term: health professional (EU, IR), health care professional (UK); guarantee (EU, a defined term), consumer guarantee (UK), commercial guarantee (MT); goods (EU), consumer goods (IR); appropriate reduction in/ of the price (EU, IR, MT), appropriate reduction in the purchase price (UK); personal security (EU, UK, IR), personal safety or security (MT). Such interventions tend to adapt terms to national usage and/or refer to a concept more precisely.

- Reduction ${ }^{20}$ : business-to-consumer commercial practices (EU, a defined term), commercial practice (UK, MT, IR); standard of special skill and care (EU, UK), standard of skill and care (IR, MT).

- Substitution - in whole or in part - of an EU term with a national term (localisation) or a newly-coined term (neologism).

- partial substitution: code of conduct (EU, a defined term; UK, MT), code of practice (IR); commercial transaction (EU, UK, MT), consumer transaction (IR); informed decision (EU, UK, MT), informed choice (IR); after-sales service (EU 2005/29/EC, 2011/83/EU), after-supply service (IR 2005; but after-sales service in the Irish transposition of 2011/83/EU); immovable property (EU 2006/114/EC, MT, UK), real property (IR; but immovable property in the Irish transposition of 2011/83/EU);

20. The terms reduction and substitution after Daille $(2017: 38,42)$. 
- full substitution - a seller (EU, a defined term in the 1990s directives; UK, IR), a trader (MT); natural person (EU 93/13/EEC; IR), individual (UK, MT, yet Malta retains a natural person in the definition of consumer in 2011); his family (2006/114/EC, UK, MT), other members of the consumer's household (IR); withdrawal (EU 2011/83/EU, MT), cancellation (UK, IR) and derived terms right to cancel (versus right of withdrawal), cancellation period, cancellation form; advertising (EU, a defined term; MT, IR), marketing communication (IR in the transposition of 2006/114/ $\mathrm{EC}$, although Ireland uses both advertisement (a defined term) and advertising in earlier transpositions) and derived terms, e.g. comparative advertising $\rightarrow$ comparative marketing communication. ${ }^{21}$

- Determinologisation through a replacement of a term with a definition or explanation. This technique interestingly imports an EU concept without a term. For example, Ireland replaces a defined EU term (definiendum), goods made to the consumer's specifications (2011/83/EU), with its definiens copied out from the definition in the directive (non-prefabricated goods made on the basis of an individual choice of or decision by the consumer), without any reference to the term itself. Similarly, Ireland does not use the term inertia selling but incorporates the description of this concept in the list of misleading commercial practices (in relation to any product that a consumer does not solicit, demanding that the consumer - (i) make immediate or deferred payment for the product, or (ii) return or keep the product safe). Thus, in both cases, an EU concept is transferred without a term.

Localisations through substitution may also be observed for collocations, e.g. take a transactional decision (2006/114/EC) replaced by make (IR); carry out the reimbursement (EU 2011/83/EU, MT, IR) replaced by a more natural make (UK); pay money (EU, UK, MT) replaced by make a payment (IR); and a consistent use of purchase a product (IR) while the EU (2006/114/EC), Malta and the UK use it interchangeably with buy a product. Some collocations change over time in the directives, e.g. cancel (93/13/EEC), rescind (1999/44/EC) and withdraw from a contract (2011/83/EU); while they are imported in early transpositions, the UK and Ireland - in contrast to Malta - replace withdraw with cancel in their transpositions of Directive 2011/83/EU to maintain consistency with the previous usage.

To sum up the integration of EU terms into national legal systems, it can have four major forms: an import, modification of an EU term, localisation (substitution with a national term) and no transfer.

21. Still the term comparative advertising may be found in Irish case law, e.g. Aldi Stores (Ireland) Limited and Aldi GMBH \& Co. KG v Dunnes Stores [2017] IECA 116. 


\subsection{Transfer of EU concepts during transposition}

Now let us consider what happens at the concept level. Similarly, the possible solutions include an import of an EU concept, its modification, localisation with a national concept and no transfer.

The prototypical situation is when the transfer of an EU term is accompanied by the transfer of an EU concept. When transposing acts import the most salient defined EU terms, they quite frequently copy their definitions, transferring the EU conceptual content, as in the example of consumer below.

consumer: shall mean any natural person who, in the contracts covered by this Directive, is acting for purposes which are not related to his trade, business or profession

$(1999 / 44 / \mathrm{EC})$

'consumer' means any natural person who, in the contracts covered by these Regulations, is acting for purposes which are outside his trade, business or profession

Irish transposing acts state explicitly that imported terms should be assigned an EU meaning and, hence, are transferred together with EU concepts, e.g. 'A word or expression that is used in this Act and is also used in the Directive shall have in this Act the same meaning as it has in the Directive'. Thanks to this framing in Irish transpositions, imported EU terms are likely to entail the transfer of the corresponding EU concepts.

EU concepts may also be imported even though their linguistic form (a term) was modified. This may be illustrated with the term advertising, which was localised with marketing communication in the Irish transposition; however, the EU definition of advertising was copied out with minor adjustments. In this case, although the term was localised at the level of linguistic expression, the EU concept was imported.

'advertising' means the making of a representation in any form in connection with a trade, business, craft or profession in order to promote the supply of goods or services, including immovable property, rights and obligations $(2006 / 114 / E C)$

'marketing communication' means any form of representation made by a trader in connection with a trade, business or profession in order to promote the supply of a product

Similarly, the Irish drafters modify the term (creating the) false impression into (making a) representation and (creating an) impression, yet they introduce the EU concept by copying out its description (with some minor localisations) and hence achieve the objective specified in the directive. 
31. Creating the false impression that the consumer has already won, will win, or will on doing a particular act win, a prize or other equivalent benefit, when in fact either:

- there is no prize or other equivalent benefit, or

- taking any action in relation to claiming the prize or other equivalent benefit is subject to the consumer paying money or incurring a cost.

$(2005 / 29 / \mathrm{EC})$

55. - (1) A trader shall not engage in any of the following commercial practices:

(v) making a representation or creating an impression that a consumer has won or will win a prize or other equivalent benefit, if -

i. there is no prize or equivalent benefit, or

ii. in claiming the prize, the consumer has to make a payment or incur a loss;

Another solution is to import EU terms or modified EU terms with the modified EU conceptual content. Such modifications were more common in the 1990s directives subject to less stringent minimum harmonisation. It can again be illustrated with the term consumer from Directive 1999/44/EC, which was transposed by Malta with a much broader scope. While in most jurisdictions the concept of consumer covers only natural persons, the Maltese definition includes legal persons indicated by the applicable minister. This concept also includes natural persons who are not immediate purchasers or beneficiaries of goods/services. In this way, the transposing act goes beyond the minimum standard and extends protection to other groups of natural or legal persons. Another example of departures from the EU concept is the term consumer goods, which was transposed in the UK through localisation:

'goods' has the same meaning as in Section 61 of the Sale of Goods Act 1979(3)

by explicit reference to the national concept defined in its Sale of Goods Act ('goods' includes all personal chattels other than things in action and money, and in Scotland all corporeal moveables except money; and in particular 'goods' includes emblements, industrial growing crops, and things attached to or forming part of the land which are agreed to be severed before sale or under the contract of sale). As a result, it applies a broader concept (cf. Twigg-Flesner 2007: 671).

Whereas it is relatively easy to assess the technique of concept transfer when a term is defined, the majority of terms used in the directives are not defined therein. There are also cases when a defined EU term is transferred without its definition, e.g. the term to materially distort the economic behaviour is imported by Ireland without a definition in contrast to the Maltese and UK transpositions. Another example is the common term financial service in the UK transposition. If 
such an EU term is identical with a well-established national term, there is a risk that it will be subconsciously understood through a more familiar national concept (unless there is an interpretation guidance as in the Irish transposing acts).

Finally, as already noted in Section 6.1, zero transfers may occur when a legal provision was not transposed.

\section{Conclusions: Term and concept transfer techniques in transposition}

We have sought to systematise transfer techniques of supranational concepts into national law. The techniques used by national drafters during transposition can be arranged along a cline from foreignization to domestication (see Chart 3).

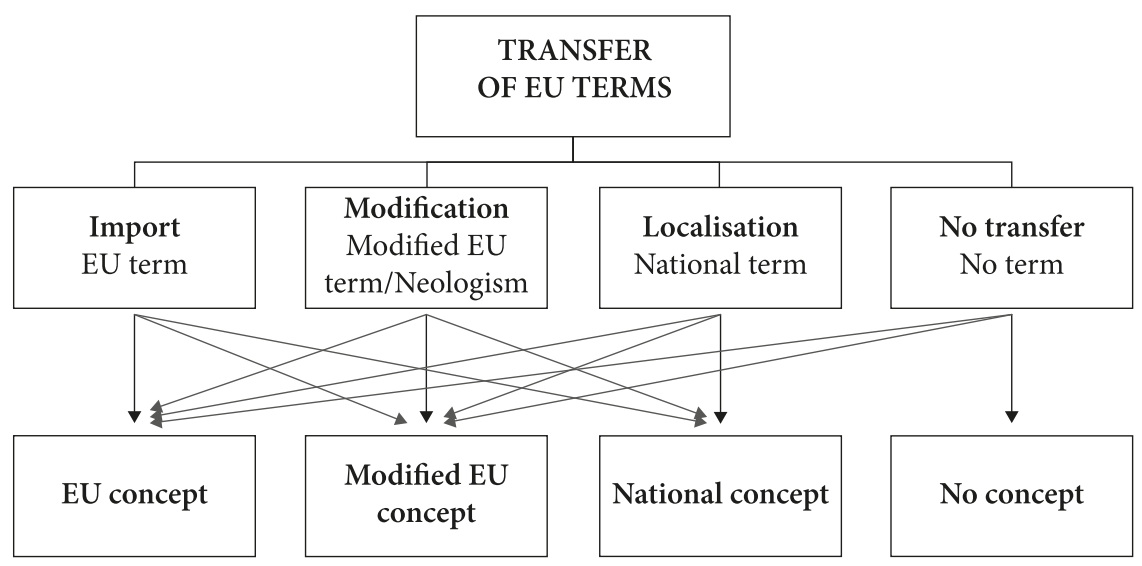

Foreignization

Domestication

Chart 3. Techniques of integrating supranational terms and concepts into national legal systems

The chart accounts both for the term level and the concept level. EU terms may be transferred into national law verbatim (import), with some modifications of the form, including neologisms, or - at the other extreme - substituted by national terms (localisation) ${ }^{22}$ or not transferred at all (zero transfer). Each transfer technique at the term level can be combined with a range of options at the concept level, that is an import of a concept, its modification, localisation or no transfer.

22. Abbamonte refers to it as domestication ('changing the language of the Directive and replacing its concepts with similar national concepts', 2007:31). 
All techniques entail a range of legal risks. An import may introduce unfamiliar terms/concepts into the national legal system, and 'there is no guarantee that the transposing measures will be understood, interpreted and applied correctly by the national courts' (Šarčević 2012: 91). As a result of modifications and localisations, which depart from EU terms, two distinct terms denote the same concept: one at the supranational level and another at the national level. This may lead to 'incoherence' between EU and national concept systems (Šarčević 2012: 91) and result in divergent interpretations of autonomous concepts by national courts and thus endanger the certainty of law (cf. Abbamonte 2007:31). Secondly, if in future the EU regulates a given policy area with regulations, such new regulations may - due to the continuity principle - be expected to use the EU terminology consistent with the preceding directive. Since regulations automatically become part of national legal systems, this would lead to a denominative variation within the national system where different terms denote the same concept: one in the directly binding EU regulation and another in the directive-transposing act. Denominative variation is considered confusing in the law. When courts are confronted with two different terminological denominations within a legal system, they are expected to assign a distinct meaning to them. Finally, national drafters practice a delicate art of balancing: whereas from the supranational perspective imports are a 'safe' technique, since they mitigate financial and political risks of inappropriate implementation, from the national perspective localisation ensures a smooth integration of new supranational concepts with the national system and maintains its integrity.

This small-scale exploratory study has examined the behaviour of EU terms and concepts during transposition into national jurisdictions, which indicates that it is a theoretically and empirically interesting area of terminological investigation. More in-depth studies are needed, including other branches of EU law and languages that do not enjoy a de facto working language status, to contribute other perspectives and a holistic insight into the behaviour of supranational terms. This will help us gain a better understanding of their nature and impact on national legal terminologies.

\section{Funding}

This work was supported by the Polish National Science Centre NCN under a grant allocated on the basis of decision no. DEC-2013/11/D/HS5/01822. 


\section{References}

Abbamonte, Giuseppe. 2007. “The Unfair Commercial Practices Directive and its General Prohibition." In The regulation of unfair commercial practices under EC directive 2005/29: new rules and new techniques, vol. Studies of the Oxford Institute of European and Comparative Law, ed. by Stephen Weatherill and Ulf Bernitz, 11-31. Oxford: Hart. Bajčić, Martina. 2017. New Insights into the Semantics of Legal Concepts and the Legal Dictionary. Amsterdam: John Benjamins. https://doi.org/10.1075/tlrp.17

Bajčić, Martina. 2018. "The Role of EU Legal English in Shaping EU Legal Culture." International Journal of Language \& Law (JLL) 7: 8-24. https://doi.org/10.14762/jll.2018.008

Biel, Łucja. 2014. Lost in the Eurofog. The Textual Fit of Translated Law. Frankfurt am Main: Peter Lang. https://doi.org/10.3726/978-3-653-03986-3

Biel, Łucja, Agnieszka Biernacka, and Anna Jopek-Bosiacka. 2018. "Collocations of Terms in EU Competition Law: a Corpus Analysis of EU English Collocations.” In Language and Law. The Role of Language and Translation in EU Competition Law, ed. by Silvia Marino, Łucja Biel, Martina Bajčić, and Vilelmini Sosoni, 249-274. Cham: Springer. https://doi.org/10.1007/978-3-319-90905-9_14

Biel, Łucja. 2019. "Theoretical and methodological challenges in researching EU legal translation." In Legal Translation. Current Issues and Challenges in Research, Methods and Applications, ed. by Ingrid Simonnæs and Marita Kristiansen, 25-39. Berlin: Frank\&Timme.

Biel, Łucja, and Vilelmini Sosoni. 2019. "EU legal culture and translation in the era of globalisation: the hybridisation of EU terminology on the example of competition law." In Legal Linguistics beyond the borders: Language and Law in a World of Media, Globalisation and Social Conflicts. Relaunching the International Language and Law Association, ed. by Friedemann Vogel, 208-229. Berlin: Duncker \& Humblot.

Binchy, William. 2011. “The Irish Legal System: An Introduction.” Legal Information Management 2: 51-155.

Bradley, Kieran St C. 2017. "Legislating in the European Union." In European Union Law. 2nd Edn., ed. by Catherine Barnard, and Steve Peers, 97-142. Oxford: Oxford University Press. https://doi.org/10.1093/he/9780198789130.003.0005

Daille, Béatrice. 2017. Term Variation in Specialised Corpora. Amsterdam/Philadelphia: John Benjamins. https://doi.org/10.1075/tlrp.19

Directorate-General for Translation (DGT), European Commission. 2016. Strategic plan 2016-2020. DG Translation. Ref. Ares(2016)1329034 - 16/o3/201; https://ec.europa.eu/info /sites/info/files/strategic-plan-2016-2020-dg-t_march2016_en.pdf. Date of access 1 Aug. 2017.

Doczekalska, Agnieszka. 2018. "Legal Languages in Contact: EU Legislative Drafting and Its Consequences for Judicial Interpretation.” In Language and Law. The Role of Language and Translation in EU Competition Law, ed. by Silvia Marino, Łucja Biel, Martina Bajčić, and Vilelmini Sosoni, 163-178. Cham: Springer.

https://doi.org/10.1007/978-3-319-90905-9_10

Donnelly, Mary and Fidelma White. 2014. Consumer Law: Rights and Regulation. Dublin: Round Hall. 
Eriksson, Ida Otken and Ulf Öberg. 2007. "The Unfair Commercial Practices Directive in Context." In The regulation of unfair commercial practices under EC directive 2005/29: new rules and new techniques. Vol. Studies of the Oxford Institute of European and Comparative Law, ed. by Stephen Weatherill and Ulf Bernitz, 91-101. Oxford: Hart. European Union. 2015. Joint Practical Guide of the European Parliament, the Council and the Commission for persons involved in the drafting of European Union legislation. Luxemboug: Publications Office of the European Union.

Faber Benítez, Pamela, Márquez Linares, Carlos and Vega Expósito, Miguel. 2005. "Framing Terminology: A Process-Oriented Approach." Meta 50(4). https://doi.org/10.7202/019916ar Fairhurst, John. 2007. Law of the European Union. 6th edn. Harlow: Pearson Longman.

Fischer, Márta. 2010. "Language (policy), translation and terminology in the European Union." In Terminology in Everyday Life, ed. by Marcel Thelen, and Frieda Steurs, 21-33. Amsterdam: John Benjamins. https://doi.org/10.1075/tirp.13.03fis

Gillespie, A. and S. Weare. 2017. The English Legal System, Oxford University Press. https://doi.org/10.1093/he/9780198785439.001.0001

General Secretariat of the Council of the EU. 2010. Manual of Precedents for Acts Established Within the Council of the European Union. <https://publications.europa.eu/en /publication-detail/-/publication/431ccffd-ooc2-491a-b423-ce7o9afod6c3/language-en> Accessed 1 Aug. 2018.

HM Government. 2018. Transposition Guidance. How to implement European Directives effectively. https://assets.publishing.service.gov.uk/government/uploads/system/uploads /attachment_data/file/682752/eu-transposition-guidance.pdf. Date of access 1 Jan. 2019.

Howells, Geraint. 2017. “European consumer law." In European Union Law. 2nd Edn., ed. by Catherine Barnard, and Steve Peers, 686-709. Oxford: Oxford University Press. https://doi.org/10.1093/he/9780198789130.003.0023

Jakobsen, Roman. 1959. “On linguistic aspects of translation.” In: On translation, edited by R.A. Brower, 232-239. Cambridge, MA: Harvard University Press.

Kilgarriff, Adam et al. 2014. “The Sketch Engine: ten years on.” Lexicography 1: 7-36. https://doi.org/10.1007/s40607-014-0009-9

Kjær, Anne Lise. 2007. "Legal translation in the European Union: A research field in need of a new approach." In Language and the Law: International Outlooks, ed. by Krzysztof Kredens, and Stanisław Goźdź-Roszkowski, 69-95. Frankfurt am Main: Peter Lang.

Kunkiel-Kryńska, Anna. 2013. Metody harmonizacji prawa konsumenckiego w Unii Europejskiej i ich wplyw na procesy implementacyjne w państwach członkowskich. Warsaw: Wolter Kluwer.

McEnery, Tony, and Andrew Hardie. 2012. Corpus Linguistics. Method, Theory and Practice. Cambridge: Cambridge University Press.

Mattila, Heikki E. S. 2013. Comparative Legal Linguistics. Language of Law, Latin and Modern Lingua Francas, 2nd Edn. (trans: C. Goddard). Aldershot: Ashgate.

Micallef, Paul Edgar. 2013. "The Future of Consumer Law - the perspective from a small island state." In The Yearbook of Consumer Law 2008, ed. by Christian Twigg-Flesner, Deborah Parry, Geraint Howells, Annette Nordhausen, 233-256. Aldershot: Ashgate.

Picht, Heribert and Jennifer Draskau. 1985. Terminology: An introduction. Guildford: University of Surrey. 
Pozzo, Barbara. 2012. "English as a Legal Lingua Franca in the EU Multilingual Context." In The Role of Legal Translation in Legal Harmonization, ed. by C. J.W. Baaij, 183-202. Alphen aan den Rijn: Kluwer Law International.

Prieto Ramos, Fernando. 2014. "International and supranational law in translation: from multilingual lawmaking to adjudication." The Translator 20 (3): 313-331. In The Role of Legal Translation in Legal Harmonization, ed. by C. J.W. Baaij, 83-107. Alphen aan den Rijn: Kluwer Law International.

Reilly, Nathan. 2009. The Effects of the Unfair Commercial Practices Directive on Irish Law. Ph.D. thesis, Dublin.

Robertson, Colin. 2015. "EU multilingual law: Interfaces of law, language and culture." In Language and culture in EU Law. Multidisciplinary perspectives, ed. by Susan Šarčević, 33-52. Farnham: Ashgate.

Robinson, William. 2017. "EU Legislation." In Legislation in Europe. A Comprehensive Guide for Scholars and Practitioners, ed. by Ulrich Karpen, and Helen Xanthaki, 229-256. Oxford and Portland: Hart.

Sager, Juan C. 1990. A Practical Course in Terminology Processing. Amsterdam: John Benamins. https://doi.org/10.1075/z.44

Sager, Juan C. 1998. “Terminology: Theory.” In: Routledge Encyclopedia of Translation Studies, ed. by Mona Baker, 258-262. London: Routledge.

Šarčević, Susan. 1997. New Approach to Legal Translation. The Hague: Kluwer Law International.

Šarčević, Susan. 2012. “Coping with the Challenges of Legal Translation in Harmonization.” In The Role of Legal Translation in Legal Harmonization, ed. by C.J.W. Baaij, 83-107. Alphen aan den Rijn: Kluwer Law International.

Schulte-Nölke, Hans. 2008. "From the Acquis Communautaire to the Common Frame of Reference - the Contribution of the Acquis Group to the DCFR." Juridica International. Law Review, 14: 27-31.

Scott, Mike. 2016. WordSmith Tools 7. Stroud: Lexical Analysis Software.

Temmerman, Rita. 2018. "European Union multilingual primary term creation and the impact of its neologisms on national adaptations." Parallèles 30(1): 8-20. https://doi.org/10.17462/para.2018.01.02

Twigg-Flesner, Christian. 2007. “Consumer Sales Directive (99/44).” In Consumer Law Compedium - A Comparative Analysis, ed. by Hans Schulte-Nölke,

Christian Twigg-Flesner, Martin Ebers, 646-712. Universitāt Bielefeld, http://citeseerx.ist .psu.edu/viewdoc/download?doi=10.1.1.183.3328\&rep=rep1\&type=pdf. Date of access 26 June 2019.

Whittaker, Sunniva. 2014. "The harmonization of legal cultures, concepts and terms. Depth of harmonization and research design." In Dynamics and Terminology: An interdisciplinary perspective on monolingual and multilingual culture-bound communication, ed. by Rita Temmerman, Marc Van Campenhoudt, 61-77. Amsterdam: John Benjamins.

Wilss, Wolfram. 1994. "Translation as a Knowledge-Based Activity: Context, Culture, and Cognition." In Language, Discourse and Translation in the West and Middle East, ed. by Robert de Beaugrande, Abdullah Shunnaq and Mohamed Helmy Heliel, 35-43. Amsterdam: John Benjamins. https://doi.org/10.1075/btl.7.o7wil

Woods, Lorna, Philippa Watson, and Marios Costa. 2017. Steiner \& Woods EU Law. 13th Edn. Oxford: Oxford University Press. https://doi.org/10.1093/he/9780198795612.001.0001 


\section{Appendix}

\section{List of directives covered by the study}

Council Directive 93/13/EEC of 5 April 1993 on unfair terms in consumer contracts (OJ L 95, 21.4.93, p. 29-34)

Directive 1999/44/EC of the European Parliament and of the Council of 25 May 1999 on certain aspects of the sale of consumer goods and associated guarantees (OJ L 171, 7.7.1999, p.12-16) Directive 2005/29/EC of the European Parliament and of the Council of 11 May 2005 concerning unfair business-to-consumer commercial practices in the internal market and amending Council Directive 84/450/EEC, Directives 97/7/EC, 98/27/EC and 2002/65/EC of the European Parliament and of the Council and Regulation (EC) No 2006/2004 of the European Parliament and of the Council (OJ L 149, 11.6.2005, p.22-39)

Directive 2006/114/EC of the European Parliament and of the Council of 12 December 2006 concerning misleading and comparative advertising (codified version) (OJ L 376, 27.12.2006, p. 21-27)

Directive 2011/83/EU of the European Parliament and of the Council of 25 October 2011 on consumer rights, amending Council Directive 93/13/EEC and Directive 1999/44/EC of the European Parliament and of the Council and repealing Council Directive 85/577/EEC and Directive 97/7/EC of the European Parliament and of the Council (OJ L 304, 22.11.2011, p. 64-88)

\section{List of UK, Irish and Maltese transposing acts}

Acts transposing Directive 93/13/EEC

UK

The Unfair Terms in Consumer Contracts Regulations 1994; No 3159 revoked and replaced by The Unfair Terms in Consumer Contracts Regulations 1999; No 2083

Consumer Rights Act 2015, Part 2, c. 15

Malta

Chapter 378 of the Laws of Malta. Consumer Affairs Act

Ireland

S.I. No. 27/1995 - European Communities (Unfair Terms in Consumer Contracts) Regulations, 1995

Acts transposing Directive 1999/44/EC

UK

The Sale and Supply of Goods to Consumers Regulations 2002, No 3045

Malta

Chapter 378 of the Laws of Malta. Consumer Affairs Act

Ireland

S.I. No. 11/2003 - European Communities (Certain Aspects of the Sale of Consumer Goods and Associated Guarantees) Regulations 2003 
Acts transposing Directive 2005/29/EC

UK

The Consumer Protection from Unfair Trading Regulations 2008 No. 1277

Malta

Chapter 378 of the Laws of Malta. Consumer Affairs Act

Ireland

S.I. No. 19/2007 Consumer Protection Act 2007

Acts transposing Directive 2006/114/EC

UK

The Business Protection from Misleading Marketing Regulations 2008, No 1276

Malta

Chapter 13 of the Laws of Malta, Commercial Code

Ireland

S.I. No. 774/2007, European Communities (Misleading and Comparative Marketing Communications) Regulations 2007

Acts transposing Directive 2011/83/EU

UK

The Consumer Contracts Regulations 2013, No 3134

Malta

Chapter 378 of the Laws of Malta, Consumer Rights Regulations, 2013

Ireland

S.I. No. 484/2013 - European Union (Consumer Information, Cancellation and Other Rights)

Regulations 2013

\section{Address for correspondence}

Eucja Biel

Institute of Applied Linguistics

University of Warsaw

ul. Dobra 55

oo-312 Warsaw

Poland

l.biel@uw.edu.pl

\section{Co-author information}

Agnieszka Doczekalska

Law School

Department of International Law and EU law

Kozminski University

adoczekalska@kozminski.edu.pl 